\title{
Visualization of Competitive Market Structure by Means of Choice Data
}

Werner Kunz*

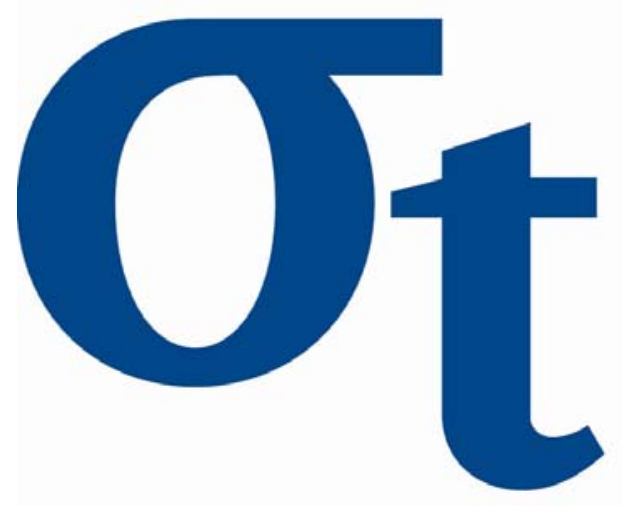

9)

$\forall$

6

* Humboldt-Universität zu Berlin, Germany

This research was supported by the Deutsche Forschungsgemeinschaft through the SFB 649 "Economic Risk". 


\title{
Visualization of Competitive Market Structure \\ by Means of Choice Data
}

\author{
Werner Kunz \\ Institute of Marketing, Humboldt-Universität zu Berlin, \\ Unter den Linden 6, D-10099 Berlin
}

\begin{abstract}
Summary
This paper presents a method for visualizing competitive market structures based on scanner panel data where asymmetries are taken into account. For this, I combined consumer choice models based on mixed logit models with three-mode principal component analysis. This approach can be used to unfold a competitive market structure map. The methodology presented is able to quantify the clout and receptivity of various brands. The results can then be visualized over time. Using this approach, guidelines for promotional activities of new brands can be provided, and possible threats from the competition detected.
\end{abstract}

Keywords: Three-mode PCA, elasticities, joint plots, market structure analysis

JEL: D49

This research was supported by the Deutsche Forschungsgemeinschaft through the SFB 649 'Economic Risk' 


\section{Motivation}

A clear picture of the competitive market structure is essential for the development of solid marketing strategies. An understanding of consumer response to marketing activities and the impact of marketing instruments are especially important (Cooper 1988). Therefore, store-tracking data in which this information is integrated is a valuable resource for brand managers.

However, some points must be noted for the analysis of market structure: First, the analysis of marketing mix variables is intrinsically tied to problems with non-symmetric effects of marketing activities across brands. Thus, the impact of a company's marketing activity can differ across the brands; and if two companies are in the same strategic group a similar effect on them is more assumable. Second, in real competitive markets, dynamic effects across time often exist. Therefore, it is possible that the balance of power within the market can change from one time segment to another, and a static analysis of the market is not very appropriate to describe such markets (Baird et al. 1988). Finally, reaction to brand activities is usually not equal for all consumers and hence consumer heterogeneity should be considered within a market structure analysis because of its significance (Kamakura and Russell 1989; Wedel et al. 1999).

The goal of a market structure analysis is to detect the interrelationships between different market brands and to evaluate their strengths and weaknesses (Elrod et al. 2002). Elasticities serve as a measure of competition within a market, and various analytical tools have been developed to analyze market structure based on elasticity matrices (Cooper and Klapper 1996; Elrod et al. 2002; Hildebrandt and Klapper 2001; Kamakura and Russell 1989; Klapper 1998). The elasticity matrices over time give insights into competitive strengths and weaknesses, reflect the asymmetries within the market and describe market structure changes over time. Therefore, an analysis of elasticity is critical to understanding competitive effects within a market. Elasticity matrices for different time periods constitute a multi-dimensional data array of the market structure. To get a realistic view of 
the market, all dimensions and the interaction effects of the complex data array should be analyzed simultaneously. Therefore, specific data-reduction procedures have been developed (Kroonenberg 1983; Smilde et al. 2004). Here, the Tucker3 model from Tucker (1966) is one of the most general approaches and has been applied very often in chemometrics (Smilde et al. 2004), psychometrics (Hofstee et al. 1997) and econometrics (Cooper and Klapper 1996; Hildebrandt and Klapper 2001).

Cooper (1988) was one of the first researchers to use multi-mode data reduction procedures to visualize market structure based on elasticity matrices. By means of the CCHM-Model, he calculated the elasticity matrices for all time periods based on aggregated retail data which were visualized by the Tucker3 approach for every week. Hildebrandt and Klapper (2001) have also used elasticity matrices for the visualization of market structure and further integrated prior knowledge of promotion activities into the estimation of the competitive situation. Both approaches used aggregated data for the visualization of the market structure. In the case of individual choice data, the data has to be aggregated, and consumer heterogeneity cannot be taken into account. Furthermore, no characteristic competitive market situations for specific time segments were estimated where a dynamic changeover of the market power from one competitive situation to another can be visualized.

Therefore, in this paper, a method of visualizing competitive market structures based on individual consumer choice data is presented. For this, I combine choice models based on mixed logit models with approaches of three-mode principal component analysis. The core matrix of the threedimensional data cube of elasticities over time can be unfolded to a competitive market structure map, and it is possible to quantify and visualize the clout and the receptivity of the brands over time. Furthermore, characteristic competitive market situations are identified, which illustrate the dynamic changeover of the market power.

\section{Elasticity Estimation as Key for the Market Interrelationships}

For the description of competitive market structure, two concepts have acquired a significant role (Cooper 1988; Kamakura and Russell 1989): The clout $\left(\mathrm{Clo}_{\mathrm{i}}\right)$ and the receptivity $\left(\mathrm{Rec}_{\mathrm{i}}\right)$ of a brand. 
Both concepts can be calculated based on the row or column elements of the elasticity matrix as follows

$\mathrm{Clo}_{\mathrm{i}}=\sum_{\mathrm{j}} \eta_{\mathrm{ji}}^{2} \quad \operatorname{Rec}_{\mathrm{i}}=\sum_{\mathrm{j}} \eta_{\mathrm{ji}}^{2}$

where $\eta_{\mathrm{ij}}$ is the price elasticity of brand $\mathrm{j}$ on the sales of brand i. Receptivity reflects the degree to which a brand is influenced by marketing activities, whereas clout indicates how a brand exerts influences on the sales of the competing brands.

The meaning of receptivity is close to the concept of brand vulnerability where the diagonal element is excluded. Thus, receptivity reflects also the influence of own marketing instruments on one's own sale. Further clout is often associated with brand strength. But high clout can also be induced by a price sensitivity of the consumer; thus brands with high clouts are not so independent in setting their price. Both receptivity and clout are central for the description of the competitive relationship and will therefore be utilized in our visualization approach.

For the analysis of disaggregated data choice models, multinomial logit models have especially gained a major role in consumer choice analysis. In this study, I use a mixed logit approach based on the finite mixture logit model. The model estimates the choice probability using a discrete mixed distribution with a maximum likelihood approach. The specification is documented by Kamakura and Russell (1989). They have also shown that the elasticities of the entire model can also be estimated based on the discrete mixture distribution, where $\mathrm{s}$ indicates the specific part of the mixture distribution and $\pi_{\mathrm{s}}$ is its share on the entire distribution. $\beta_{\mathrm{s}}$ is the estimated effect coefficient and $\mathrm{P}_{\mathrm{si}}$ is the choice probability for brand $\mathrm{i}$ given $\mathrm{s}$.

$$
\eta_{\mathrm{ii}}=\sum_{\mathrm{s}=1}^{\mathrm{S}} \frac{\pi_{\mathrm{s}} \mathrm{P}_{\mathrm{si}}}{\sum_{\mathrm{s}} \mathrm{P}_{\mathrm{si}}} \beta_{\mathrm{s}}\left(1-\mathrm{P}_{\mathrm{si}}\right) \mathrm{x}_{\mathrm{i}}, \eta_{\mathrm{ij}}=-\sum_{\mathrm{s}=1}^{\mathrm{S}} \sum_{\mathrm{s}}^{\pi_{\mathrm{s}} \mathrm{P}_{\mathrm{si}}} \beta_{\mathrm{s}} \mathrm{P}_{\mathrm{sj}} \mathrm{x}_{\mathrm{j}}, \quad \sum_{\mathrm{s}=1}^{\mathrm{S}} \pi_{\mathrm{s}}=1
$$




\section{Theory of the Three-Mode Analysis}

\section{The decomposition of the Tucker3 model}

In the following, the fundamentals of the three-mode principal component analysis are briefly described, and an estimation approach for the Tucker3 model is presented. Further information about multi-mode data approaches can be obtained by Kroonenberg (1983) or Smilde, Bro \& Geladi (2004). The basis of three-mode principal component analysis is a three-dimensional $(I \times J \times K)$-data array $\mathrm{X}$, where every dimension is related to one mode (i.e. mode $\mathrm{A}, \mathrm{B}$, and $\mathrm{C}$ ).

Ledyard R. Tucker (1966) was the first to develop a model to analyze three-mode data arrays by integrating the cross-mode interaction effects. The Tucker3 model is a very general specification for data analysis and covers several other models (e.g. PCA, SVD, WPCA, Tucker2, PARAFAC). The major idea of this model is to conduct PCA on the mode level simultaneously, while the relationships between the modes remain in a core matrix. The data is composed on every mode level to specific components which are described by factor-loading matrices A, B, and C as well as a core matrix $\mathrm{G}$ of the component interrelationships ( $\mathrm{G}$ is specified here as a $(\mathrm{P} \times \mathrm{Q} \times \mathrm{R})$-data array). Following the Tucker3 model, the three-dimensional data array $\mathrm{X}$ can be decomposed in the subsequent form using the slide notation of $\mathrm{X}$ as $(I \times J)$-matrix. By means of the unfolded form of $\mathrm{X}$ as $(I \times J \cdot K)$-matrix and the kronecker product $\otimes$, it is possible to express the relationships in a more condensed form.

$$
\mathrm{X}_{\mathrm{k}}=\mathrm{A} \sum_{\mathrm{r}=1}^{\mathrm{R}} \mathrm{c}_{\mathrm{kr}} \mathrm{G}_{\mathrm{r}} \mathrm{B}^{\prime}+\mathrm{E}_{\mathrm{r}} \quad \mathrm{k}=1 \mathrm{KK} \quad \text { or } \quad \mathrm{X}^{0}=\mathrm{A} G^{\mathrm{Q}}(\mathrm{C} \otimes \mathrm{B})^{\prime}+\mathrm{E}
$$

where $G_{r}$ and $E_{r}$ are the $r$-th slide of the core matrix $G$ and the residual matrix $E$. The solution of the Tucker3 model is in general not unique. If $\mathrm{A}, \mathrm{B}$, and $\mathrm{C}$ are orthonormal and transformed by orthonormal matrices $\mathrm{O}, \mathrm{P}$, and $\mathrm{Q}$, then a counter-rotation of the core matrix $\mathrm{G}$ exists to neutralize this.

$$
\hat{\mathrm{A}}=\mathrm{AO}, \quad \hat{\mathrm{B}}=\mathrm{BP}, \quad \hat{\mathrm{C}}=\mathrm{CQ} \Rightarrow \hat{\mathrm{G}}=\mathrm{O}^{\prime}\left(\hat{\xi}(\mathrm{Q} \otimes \mathrm{P}), \quad \mathrm{X}^{\prime}=\hat{\mathrm{A}} \hat{\mathrm{G}}(\hat{\mathrm{C}} \otimes \hat{\mathrm{B}})^{\prime}\right.
$$


Therefore, rotation procedures for factor structure simplification (e.g. Varimax or Oblimin) can also be applied and used for a better interpretation of the solution.

\section{Estimation of the Tucker3 model}

To determine the solution of the Tucker3 model, the residual matrix E has to be minimized. One of the most prominent approaches is the Alternating Least Square Approach (TuckALS3) of Kroonenberg and de Leeuw (1980). The optimization problem can be specified as follows:

$$
\min _{A, B, C, G}\left\|\widetilde{X}-A \widetilde{G}(C \otimes B)^{\prime}\right\|^{2}
$$

If the mode matrices $\mathrm{A}, \mathrm{B}$, and $\mathrm{C}$ are restricted to be orthonormal, the core matrix $\mathrm{G}$ can be calculated based on $\mathrm{A}, \mathrm{B}, \mathrm{C}$ and $\mathrm{X}$ (i.e. $\mathrm{G}=\mathrm{A}^{\prime} \mathrm{X}(\mathrm{C} \otimes \mathrm{B})$ ) and only a solution for $\mathrm{A}, \mathrm{B}$, and $\mathrm{C}$ must be found. Further, it can be shown that A is an eigenvector matrix of the following specific SVD:

$$
\mathrm{X}=\mathrm{AG}(\mathrm{C} \otimes \mathrm{B})^{\prime} \quad \Rightarrow \quad[\mathrm{A}, \mathrm{D}, \mathrm{V}]=\operatorname{svd}\left(\mathrm{X}\left(\mathrm{CC} \otimes \mathrm{BB}^{\prime}\right)\right)
$$

The TuckALS3-algorithm starts with three arbitrary orthonormal initial matrices of A, B, and C and estimates alternating updates of each mode matrix based on the other and the data array X until an exit criteria is reached (e.g. square sum of residuals). Kroonenberg showed that the algorithm converged if A, B, and C are orthonormal (Kroonenberg 1983). Andersson and Bro (1998) showed that for the estimation of the eigenvector matrices within the TuckALS3-algorithm, the Nonlinear Iterative Partial Least Squares (NIPALS)-algorithm is one of the most efficient approaches. Restrictions on the matrices can be implemented if the restricted parameters are recovered to their initial values after each updating iteration (Hildebrandt and Klapper 2001).

\section{Visualization of the Tucker3 model}

The interpretation of the core matrix can become quite complicated. One possibility for the interpretation is to visualize the core matrix by means of joint plots (Kroonenberg 1983). For this, the product of the core matrix slides $\mathrm{G}_{\mathrm{r}}$ and the two mode matrices $\mathrm{A}$ and $\mathrm{B}$ (defined as the inner 
product matrix $\mathrm{IP}_{\mathrm{r}}$ of the $\mathrm{r}$-th component of $\mathrm{C}$ ) can be decomposed into two equally sized matrices by means of SVD of the core matrix slides $G_{r}$, in the following form

$$
\begin{aligned}
& G_{r}=U_{r} \Lambda_{r} V_{r}^{\prime} \\
& I P_{r}=A G_{r} B^{\prime}=A U_{r} \Lambda_{r} V_{r}^{\prime} B^{\prime}=\left(\sqrt[4]{\frac{I}{J}} A U_{r} \Lambda_{r}^{\frac{1}{2}}\right)\left(\sqrt[4]{\frac{J}{I}} B V_{r} \Lambda_{r}^{\frac{1}{2}}\right) \quad(r=1 \mathrm{~K} R)
\end{aligned}
$$

where $\Lambda_{\mathrm{r}}$ is a diagonal matrix of the singular values; $U_{\mathrm{r}}$ and $\mathrm{V}_{\mathrm{r}}$ are the orthonormal eigenvector matrices of the SVD. The two parts of this decomposition represent the elements of the modes A and $\mathrm{B}$ in a joint space, and the dimension of this space depends on the number of extracted singular values. The joint plot is rotational invariant. If an element is far away from the origin, it indicates a strong impact of this element on all other elements. Two elements of the same mode are similar if the distance between them is low. Two elements of different modes correspond to each other if the angle between them is low and both elements are relatively far away from the origin. The inner product matrices can be used to estimate idealized slides of $\mathrm{X}$ and it is later used to estimate idealized elasticities for specific competitive situations. To estimate the idealized slides, the inner product matrices were weighted by the factor loadings of predefined characteristic weeks.

$$
\mathrm{A} \times \mathrm{B}_{\mathrm{s}}=\sum_{\mathrm{r}=1}^{\mathrm{R}} \mathrm{c}_{\mathrm{sr}} \mathrm{IP}_{\mathrm{r}} \quad \mathrm{s} \in \mathrm{S} \subseteq \mathrm{K}
$$

\section{Visualization of the Market Structure}

In the following, I demonstrate the strengths of visualizing the competitive structure of a specific market. The necessary analyzing procedures have been implemented in the Matlab software package. The application is based on scanner panel data provided by the GFK, Nuremberg. I used consumer choice data of personal-care products which cover the purchase behavior of 1,905 households over a period of 52 weeks. The market is dominated by eight brands which comprise $72 \%$ of the total market. In the following, these brands are referred to as Brand 1 to Brand 8 for confidentiality reasons. 
The marketing activities considered are price, display and feature of every competitor per week. The paid price, the use of displays and features were explicitly reported in the raw data for the specific chosen brand. The marketing instruments of the competition are calculated based on the weekly mean values. To avoid multi-colinearity problems, a new variable "promotion" is introduced which indicates the joint use of display and feature for a brand. Accordingly, "display" and "feature" indicate only the exclusive use of a display or a feature. Table 1 shows the market shares, the mean price, the number of promotion, display, and feature weeks of the eight brands over the complete period of time. Because features are seldom used exclusively, I only consider price, promotion and display in the further analysis.

\begin{tabular}{lrrrrrrrr}
\hline & Brand 1 & Brand 2 & Brand 3 & Brand 4 & Brand 5 & Brand 6 & Brand 7 & Brand 8 \\
\hline MS & 6.0 & 8.4 & 4.8 & 8.6 & 12.3 & 15.9 & 4.6 & 11.0 \\
Price & .70 & .73 & .64 & .66 & .95 & .69 & .59 & .74 \\
Promotion & 1 & 2 & 4 & 9 & 6 & 9 & 0 & 7 \\
Display & 6 & 7 & 18 & 15 & 16 & 24 & 0 & 23 \\
Feature & 0 & 0 & 3 & 9 & 0 & 2 & 0 & 3 \\
\hline
\end{tabular}

Table 1: Description of the data set

\section{Estimation of elasticity over time}

For the estimation of the price-elasticities, a mixed logit approach based on the finite mixture logit model is used (Train 2003). The underlying choice model is based on a random utility model, where the choice utility $(\mathrm{U})$ of the brand $\mathrm{i}$ for customer $\mathrm{n}$ is specified as follows

$\mathrm{U}_{\mathrm{sni}}=\alpha_{\mathrm{i}}+\beta_{1 \mathrm{~s}} \cdot$ Price $_{\mathrm{i}}+\beta_{2 \mathrm{~s}} \cdot$ Prom $_{\mathrm{i}}+\beta_{3 \mathrm{~s}} \cdot$ Display $_{\mathrm{i}}+\varepsilon_{\mathrm{i}} \quad \varepsilon_{\mathrm{i}} \in \mathrm{EV}\left(0, \frac{\pi^{2}}{6}\right)$

where $\mathrm{s}$ indicates the index of the mixture distribution and $\varepsilon_{\mathrm{i}}$ is the extreme value distributed residual term of the utility. Furthermore, a brand-specific constant $\alpha_{\mathrm{i}}$ is estimated for every brand. Based on this, the maximum likelihood estimator of the finite mixture logit approach is specified and the estimation is done for every week separately. Thus, time interdependencies of the purchases 
were kept in the result of these estimations and were analyzed later by the tucker model. The price elasticities per week were estimated by the approach of Kamakura and Russell (1989).

Price-elasticity effects in a real market vary extremely over time if they are calculated on short periods. This can be caused by short-term context effects that are not integrated into the model (e.g. promotion that is not reported, income effects at the end of the month). Because I am interested in the major development of the market structure, such short-term effects can be interpreted as noise. To avoid an over-fitting of the elasticities on such short-term effects, I integrate the adjacent weeks in the parameter estimation per week. This procedure will smooth the estimation in the sense of moving average (Hamilton 1999). If the focus of the analysis would be the description of a predefined specific market scenario, such an approach is not recommendable. For this, Hildebrandt and Klapper (2001) have shown an approach where a predefined market situation can be integrated into the estimation of a constrained Tucker3 model.

Because the sample size of the dataset per week is relatively small (132 purchases per week on average), the heterogeneity of the dataset is considered by a two segment finite mixture distribution and no store dummy variables were integrated into the model. A more sophisticated model may fit the data better, but the stability of the estimation for every week cannot be ensured. Further, I expected the purchase decisions of one household per week to be independent, because purchase incidents of the underlining product usually do not happen more than once per week. As a result of the choice model, I got a three-mode data array consisting of price-elasticities of all brands for every week.

\section{Estimation of the Tucker3 model}

For the calculation of the Tucker3 model I applied the TuckALS3-algorithm proposed by Kroonenberg and de Leew (1980). For the initial solution of the algorithm, random matrices for A, $\mathrm{B}$ and $\mathrm{C}$ are used and the NIPALS-Algorithm applied for the SVD within each iteration,. The estimation of the Tucker3 model mainly relies on the N-way toolbox developed by Andresson and Bro (2000) for the Matlab software environment. 
To detect the right mode configuration, different configurations from $(1 \times 1 \times 1)$ until $(5 \times 5 \times 9)$ were estimated and compared by the marginal increase of explained variance. The last high increase of variance is contributed by the $(5 \times 5 \times 3)$-configuration and the explained variance for this is total $92 \%$. The stability of the solution was tested by a split half-method. The correlation between the different parameter estimation was .98 . Furthermore, the residual plot of the three-mode data array was observed and shows in total a good fit of the solution with the original data. No characteristic pattern could be detected.

\begin{tabular}{|c|c|c|c|c|c|c|c|c|c|c|}
\hline & A1 & A2 & A3 & A4 & A5 & B1 & B2 & B3 & B4 & B5 \\
\hline Brand 1 & -.01 & -.01 & -.04 & -.20 & .79 & .02 & .09 & -.21 & -.54 & .35 \\
\hline \multirow[t]{2}{*}{ Brand 2} & -.02 & -.04 & .02 & .29 & .39 & -.01 & .03 & -.12 & .06 & .19 \\
\hline & & & & & & 1,0 & & & & \\
\hline Brand 3 & .98 & -.03 & -.01 & -.02 & -.01 & $\mathbf{0}$ & .00 & .00 & .00 & .00 \\
\hline Brand 4 & -.04 & .92 & -.03 & -.06 & -.02 & .00 & .99 & .01 & .01 & -.02 \\
\hline Brand 5 & -.01 & -.02 & .99 & -.03 & -.02 & .00 & .02 & .96 & -.03 & .06 \\
\hline Brand 6 & -.17 & -.37 & -.13 & -.36 & -.13 & .00 & -.03 & .08 & .07 & .90 \\
\hline Brand 7 & -.02 & -.03 & .03 & .25 & .44 & -.01 & .02 & -.09 & -.05 & .11 \\
\hline Brand 8 & -.04 & -.08 & -.06 & .83 & -.13 & .01 & .04 & -.10 & .83 & .15 \\
\hline
\end{tabular}

Exp.

$\begin{array}{lllllllllll}\text { Variance } & .29 & .21 & .25 & .11 & .14 & .24 & .18 & .42 & .05 & .13\end{array}$

Table 4: Factor loadings of A and B 


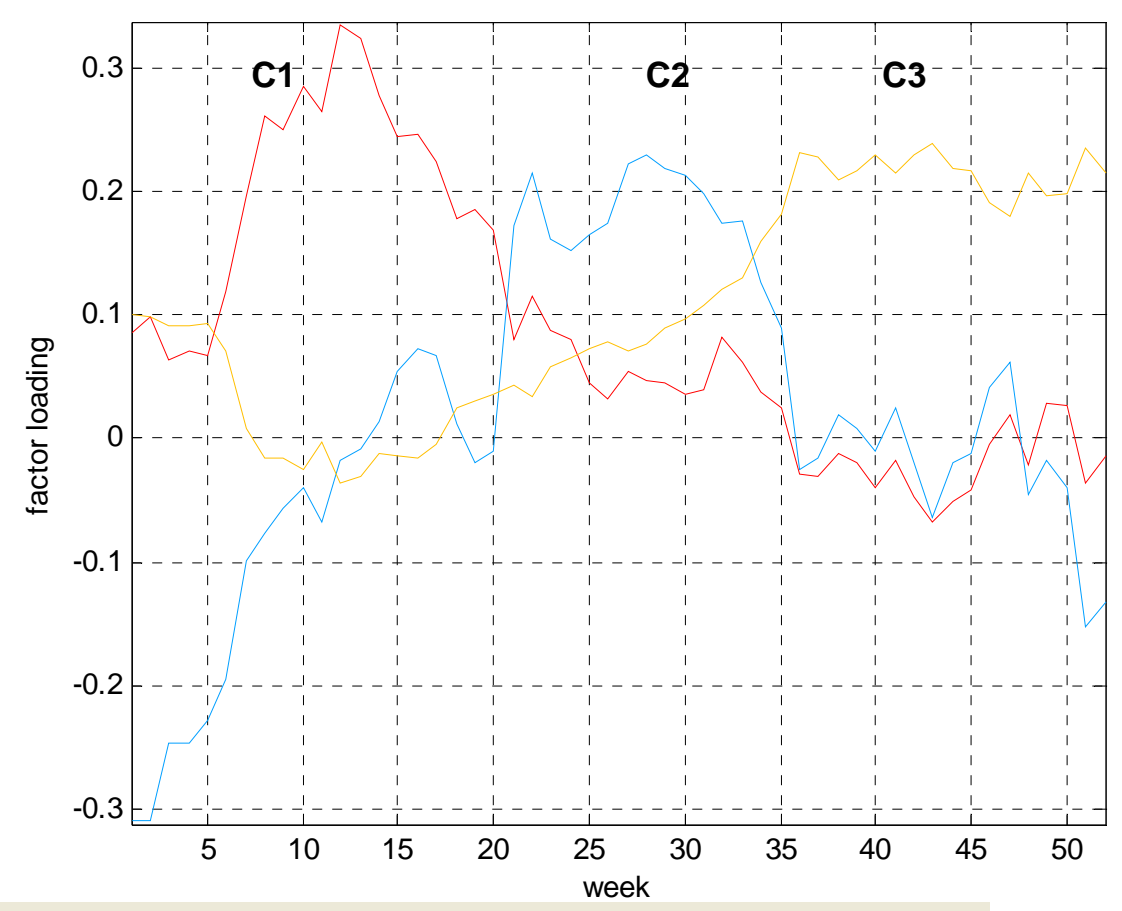

Figure 1: Factor loadings of mode C

$$
\text { C1 }(\exp \text { Var. }=.10) \quad \text { C2 }(\exp \text { Var. }=.11)
$$

$\begin{array}{llllllllll}\text { B1 } & \text { B2 } & \text { B3 } & \text { B4 } & \text { B5 } & \text { B1 } & \text { B2 } & \text { B3 } & \text { B4 } & \text { B5 }\end{array}$

\begin{tabular}{lrrrrrrrrrr}
\hline A1 & 5.5 & 2.0 & -5.4 & -.9 & -1.5 & -22.2 & 3.6 & 3.3 & 3.1 & 9.7 \\
A2 & 1.4 & -12.1 & -.4 & 1.8 & 4.8 & 1.1 & -4.6 & -1.7 & 1.1 & 4.7 \\
A3 & -2.3 & -.2 & -35.1 & 6.4 & -3.7 & 1.1 & -.6 & -27.1 & 4.7 & 2.4 \\
A4 & -1.2 & 1.5 & 15.6 & -11.8 & -3.1 & 1.3 & -.3 & 14.4 & -14.9 & 4.4 \\
A5 & -.4 & 3.6 & 14.8 & 8.5 & -1.6 & 1.3 & -1.7 & $\mathbf{2 1 . 4}$ & 16.2 & -2.6 \\
\hline \multicolumn{7}{c}{ C3 $(\exp$ Var. $=.79)$}
\end{tabular}

$\begin{array}{lllll}\text { B1 } & \text { B2 } & \text { B3 } & \text { B4 } & \text { B5 }\end{array}$

\begin{tabular}{rrrrrr}
\hline A1 & $\mathbf{- 6 9 . 9}$ & 15.1 & 3.7 & 7.5 & $\mathbf{3 0 . 3}$ \\
A2 & 6.2 & $-\mathbf{5 9 . 1}$ & .6 & 5.4 & $\mathbf{3 3 . 6}$ \\
A3 & .9 & 1.9 & $\mathbf{- 6 0 . 2}$ & 11.7 & 3.9 \\
A4 & 3.6 & 6.9 & $\mathbf{3 6 . 3}$ & -6.4 & 19.6 \\
A5 & 6.5 & 11.4 & $\mathbf{4 0 . 6}$ & 6.2 & 17.9
\end{tabular}

Table 5: Core matrix of the Tucker3 solution 
To ensure a better interpretation of the results, I applied VARIMAX-Rotation and further orthonormal transformation to the mode matrices A, B, and C. The mode A indicates the receptivity and mode $\mathrm{B}$ the clout of the different brands. Mode $\mathrm{C}$ represents a time mode consisting of 52 weeks. The resulting factor loading matrices for A and B are shown in Table 4. The loadings of the three components of $\mathrm{C}$ are illustrated in Figure 1.

The time mode $\mathrm{C}$ is decomposed into three components. It can be clearly seen that the components split the 52 weeks in three major parts (weeks 6-20 $\rightarrow \mathrm{C} 1$; weeks 20-33 $\rightarrow \mathrm{C} 2$; 33-52 $\rightarrow \mathrm{C} 3$ ). The most part of the variance is explained by the last component $\mathrm{C} 3$. The relations between the different modes are represented by the core matrix which is shown in Table 5 (unfolded form).
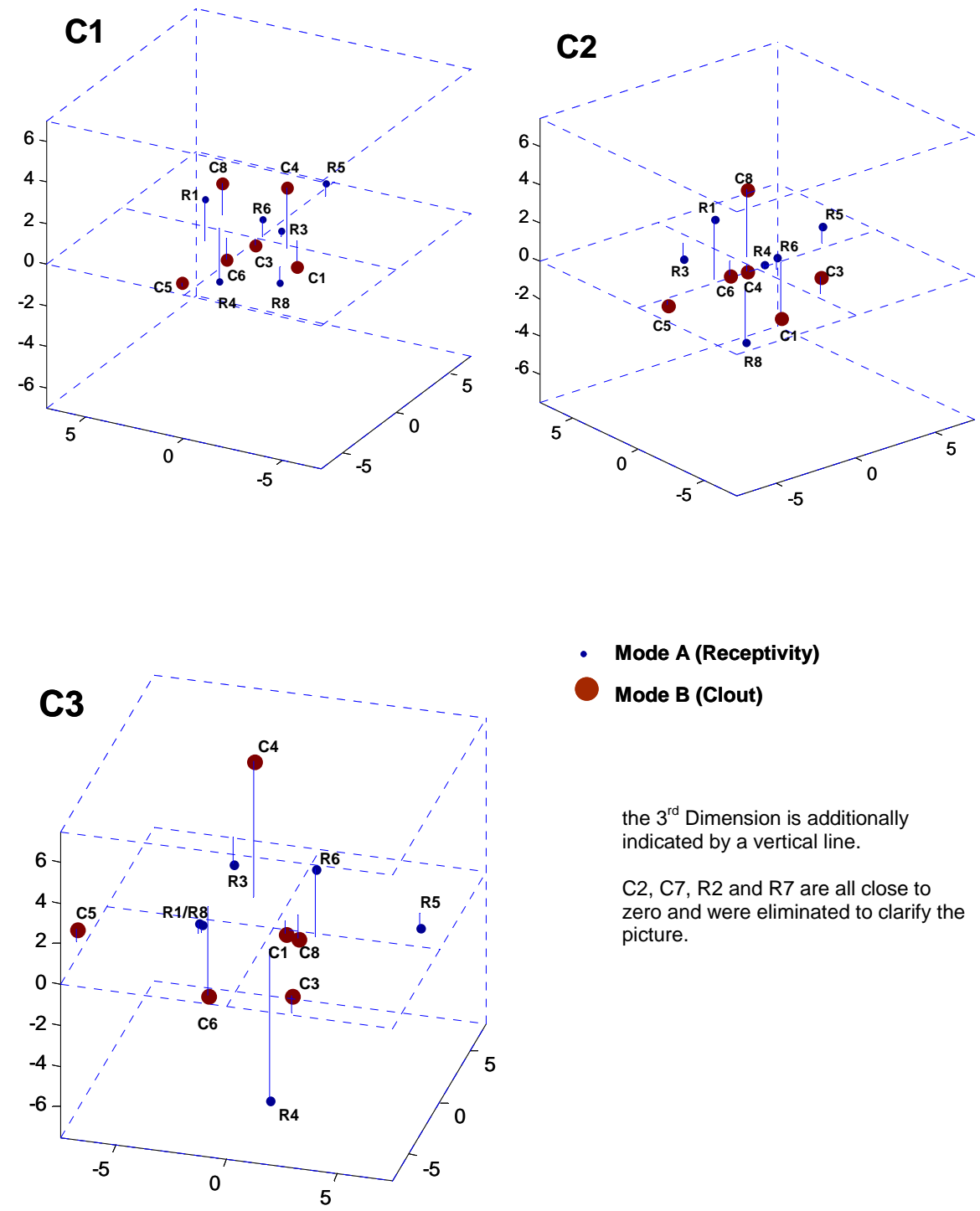

- Mode A (Receptivity)

Mode B (Clout)

the $3^{\text {rd }}$ Dimension is additionally indicated by a vertical line.

C2, C7, R2 and R7 are all close to zero and were eliminated to clarify the picture.

Figure 2: Joint plots of the three core slides 


\section{Graphical illustration of the core matrix}

For the interpretation of the market structure, joint plots of each time component were calculated based on the Tucker3 solution. Because in all time components the contribution of the third dimension is critical for the visualization, I decide to unfold three dimensional joint plots $(\mathrm{C} 1$ : 2D:67,7\% 3D: 86,4\%; C2: 2D:63,9\% 3D: 88,8\%; C3: 2D:61,7\% 3D: 86,7\%). The plots of the three time components are shown in Figure 2.

Based on the inner products, an idealized elasticity matrix can be calculated (idealized criteria: factorloadings $\geq .1$ ). The receptivity and clout of the brands relative to the mean value in every scenario are further measurements to illustrate the power balance within every time component. The results are plotted in a two-dimensional space. For the three time components, the plots are shown in Figure 3.

The plots indicate the dominance of Brand 5 in the first time component and the rise of Brand 3 and later of Brand 4 in the following time components, while the partial rise of Brand 8 and Brand 1 in the second time component can also be observed. The relative receptivity-clout-plot shows the power relationships within a market structure for the different time components, but detailed information about the interaction effects within specific competitive groups are not visualized by this plot. 


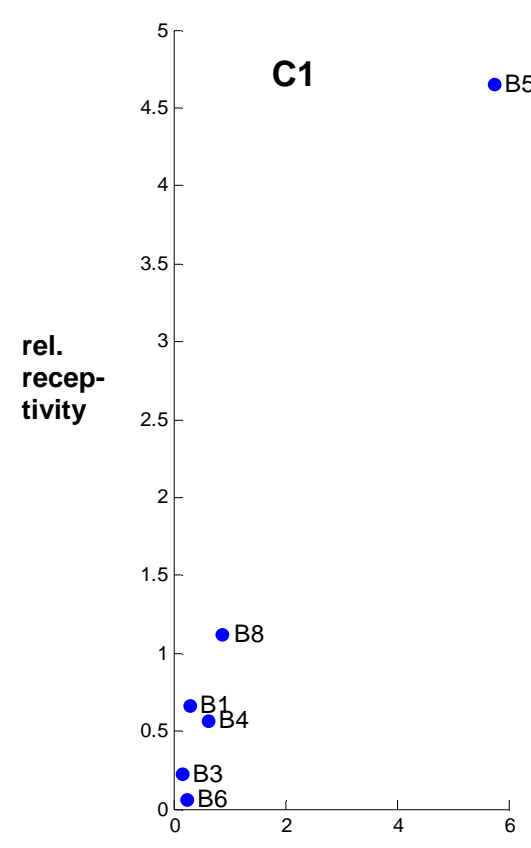

rel. clout

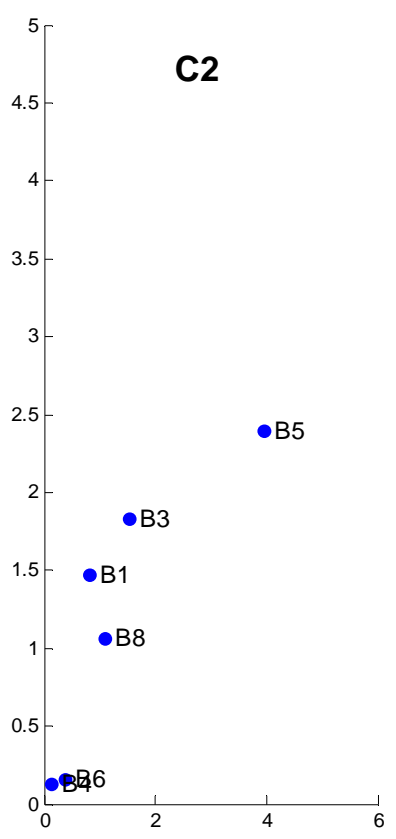

rel. clout

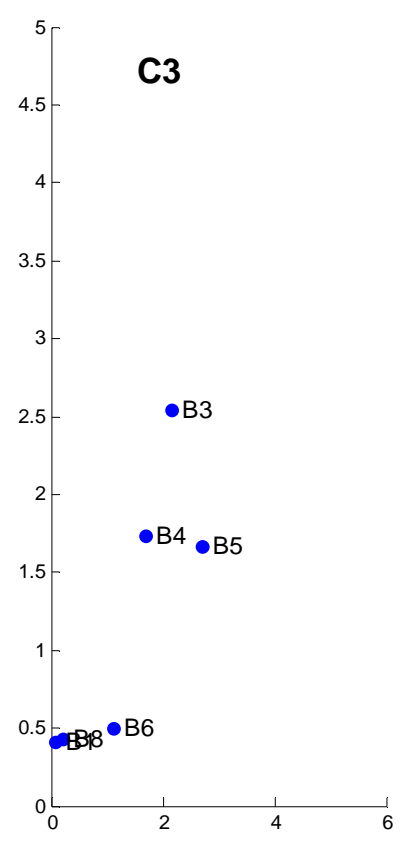

rel. clout

Figure 3: Relative receptivity and clout for the different time components

\section{Summary}

This paper presents a method for visualizing competitive market structures based on consumer choice behavior affected by different marketing activities. For this, a combination of consumer choice models with approaches of $\mathrm{n}$-way data analysis is used. The approach significantly reduces the complexity of competitive relations in the data and obtains interaction effects between the different dimensions simultaneously. Furthermore, elasticity changes between specific time components can be visualized over time and asymmetries between the brands are considered.

Our methodology used scanner panel data which is becoming more and more available for companies. Even small and medium-sized enterprise can today participate from this information at lower rates. Even though today store-tracking data are easy to achieve, managers who are responsible for planning are mostly overstrained by vast amounts of data. With this approach I have shown an easy way to reduce this amount of information into a compact form from which deep managerial implications can be derived. 
It allows the detection of relative power of different brands for specific time components. Furthermore, interaction effects between the brands can be visualized and specific groups of competition can be identified. The methodology presented is also able to quantify and visualize the clout and receptivity or vulnerability between brands. By means of this, potential threats and own weaknesses can be noticed at an early stage.

The application has been focused on price promotion, but also other marketing instruments can be taken as a basis for the visualization. Hence, the method can give managerial guidance for holistic promotional planning. Thus, the relevant competitors can be detected, where the price competition is important, while other competitive groups can be identified if considering a display campaign.

\section{References}

Andersson, Claus A. and Rasmus Bro (1998), "Improving the speed of multi-way algorithms: Part I. Tucker3," Chemometrics \& Intelligent Laboratory Systems, 42 (1), 93-103.

---- (2000), "The N-way Toolbox for Matlab," Chemometrics \& Intelligent Laboratory Systems, 52 (2), 1-4.

Baird, Inga S., D. Sudharshan, and Howard Thomas (1988), "Addressing Temporal Change in Strategic Group Analysis: A Three-Mode Factor Analysis Approach," Journal of Management, 14 (3), 425-39.

Cooper, Lee G. (1988), "Competitive Maps: The Structure Underlying Asymmetric Cross Elasticities," Management Science, 34 (6), 707-23.

Cooper, Lee G. and Daniel Klapper (1996), "Competitive-component analysis: A new approach to calibrating asymmetric market-share models," Journal of Marketing Research, 33 (2), 224.

Elrod, Terry, Gary J. Russell, Allan D. Shocker, Rick L. Andrews, Lynd Bacon, Barry L. Bayus, J. Douglas Carroll, Richard M. Johnson, Wagner A. Kamakura, Peter Lenk, Josef A. Mazanec, Vithala R. Rao, and Venkatesh Shankar (2002), "Inferring Market Structure from Customer Response to Competing and Complementary Products," Marketing Letters, 13 (3), 221-32. 
Hamilton, James (1999), Time Series Analysis. Princton: Princton University Press.

Hildebrandt, Lutz and Daniel Klapper (2001), "The analysis of price competition between corporate brands," International Journal of Research in Marketing, 18 (1/2), 139-59.

Hofstee, Willem K. B., Henk A. L. Kiers, Boele De Raad, Lewis R. Goldberg, and Fritz Ostendorf (1997), "A Comparison of Big-Five structures of personality traits in Dutch, English, and German," European Journal of Personality, 11 (1), 15-31.

Kamakura, Wagner A. and Gary J. Russell (1989), "A Probabilistic Choice Model for Market Segmentation and Elasticity Structure," Journal of Marketing Research, 26 (4), 379-90.

Klapper, Daniel (1998), Die Analyse von Wettbewerbsbeziehungen mit Scannerdaten. Berlin: Springer.

Kroonenberg, Pieter M. (1983), Three-mode Principal Component Analysis. Theory and Applications. Leiden: DSWO Press.

Kroonenberg, Pieter M. and J. de Leew (1980), "Principal Component Analysis of Three-Mode Data by Means of Alternating Least Squares Algorithms," Psychometrika, 45 (1), 69-97.

Smilde, Age, Rasmus Bro, and Paul Geladi (2004), Multi-way Analysis - Applications in the Chemical Sciences. Chichester: Wiley.

Train (2003), Discrete Choice Methods with Simulation. Boston: Cambridge University Press.

Tucker (1966), "Some mathematical notes on three-mode factor analysis," Psychometrika, 31 (3), 279-311.

Wedel, Michel, Wagner Kamakura, Neeraj Arora, Albert Bemmaor, Chiang Jeongwen, Terry Elrod, Rich Johnson, Peter Lenk, Scott Neslin, and Carsten Stig Poulsen (1999), "Discrete and Continuous Representations of Unobserved Heterogeneity in Choice Modeling," Marketing Letters, 10 (3), 219-32. 


\section{SFB 649 Discussion Paper Series 2007}

For a complete list of Discussion Papers published by the SFB 649, please visit http://sfb649.wiwi.hu-berlin.de.

001 "Trade Liberalisation, Process and Product Innovation, and Relative Skill Demand" by Sebastian Braun, January 2007.

002 "Robust Risk Management. Accounting for Nonstationarity and Heavy Tails" by Ying Chen and Vladimir Spokoiny, January 2007.

003 "Explaining Asset Prices with External Habits and Wage Rigidities in a DSGE Model." by Harald Uhlig, January 2007.

004 "Volatility and Causality in Asia Pacific Financial Markets" by Enzo Weber, January 2007.

005 "Quantile Sieve Estimates For Time Series" by Jürgen Franke, JeanPierre Stockis and Joseph Tadjuidje, February 2007.

006 "Real Origins of the Great Depression: Monopolistic Competition, Union Power, and the American Business Cycle in the 1920s" by Monique Ebell and Albrecht Ritschl, February 2007.

007 "Rules, Discretion or Reputation? Monetary Policies and the Efficiency of Financial Markets in Germany, 14th to 16th Centuries" by Oliver Volckart, February 2007.

008 "Sectoral Transformation, Turbulence, and Labour Market Dynamics in Germany" by Ronald Bachmann and Michael C. Burda, February 2007.

009 "Union Wage Compression in a Right-to-Manage Model" by Thorsten Vogel, February 2007.

010 "On $\sigma$-additive robust representation of convex risk measures for unbounded financial positions in the presence of uncertainty about the market model" by Volker Krätschmer, March 2007.

011 "Media Coverage and Macroeconomic Information Processing" by Alexandra Niessen, March 2007.

012 "Are Correlations Constant Over Time? Application of the CC-TRIG to Return Series from Different Asset Classes." by Matthias Fischer, March 2007.

013 "Uncertain Paternity, Mating Market Failure, and the Institution of Marriage" by Dirk Bethmann and Michael Kvasnicka, March 2007.

014 "What Happened to the Transatlantic Capital Market Relations?" by Enzo Weber, March 2007.

015 "Who Leads Financial Markets?" by Enzo Weber, April 2007.

016 "Fiscal Policy Rules in Practice" by Andreas Thams, April 2007.

017 "Empirical Pricing Kernels and Investor Preferences" by Kai Detlefsen, Wolfgang Härdle and Rouslan Moro, April 2007.

018 "Simultaneous Causality in International Trade" by Enzo Weber, April 2007.

019 "Regional and Outward Economic Integration in South-East Asia" by Enzo Weber, April 2007.

020 "Computational Statistics and Data Visualization" by Antony Unwin, Chun-houh Chen and Wolfgang Härdle, April 2007.

021 "Ideology Without Ideologists" by Lydia Mechtenberg, April 2007.

022 "A Generalized ARFIMA Process with Markov-Switching Fractional Differencing Parameter" by Wen-Jen Tsay and Wolfgang Härdle, April 2007.

\section{SFB 649, Spandauer Straße 1, D-10178 Berlin} http:/ / sfb649.wiwi.hu-berlin.de 
023 "Time Series Modelling with Semiparametric Factor Dynamics" by Szymon Borak, Wolfgang Härdle, Enno Mammen and Byeong U. Park, April 2007.

024 "From Animal Baits to Investors' Preference: Estimating and Demixing of the Weight Function in Semiparametric Models for Biased Samples" by Ya'acov Ritov and Wolfgang Härdle, May 2007.

025 "Statistics of Risk Aversion" by Enzo Giacomini and Wolfgang Härdle, May 2007.

026 "Robust Optimal Control for a Consumption-Investment Problem" by Alexander Schied, May 2007.

027 "Long Memory Persistence in the Factor of Implied Volatility Dynamics" by Wolfgang Härdle and Julius Mungo, May 2007.

028 "Macroeconomic Policy in a Heterogeneous Monetary Union" by Oliver Grimm and Stefan Ried, May 2007.

029 "Comparison of Panel Cointegration Tests" by Deniz Dilan Karaman Örsal, May 2007.

030 "Robust Maximization of Consumption with Logarithmic Utility" by Daniel Hernández-Hernández and Alexander Schied, May 2007.

031 "Using Wiki to Build an E-learning System in Statistics in Arabic Language" by Taleb Ahmad, Wolfgang Härdle and Sigbert Klinke, May 2007.

032 "Visualization of Competitive Market Structure by Means of Choice Data" by Werner Kunz, May 2007. 